\title{
Dying individuals and suffering populations: applying a population-level bioethics lens to palliative care in humanitarian contexts: before, during and after the COVID-19 pandemic
}

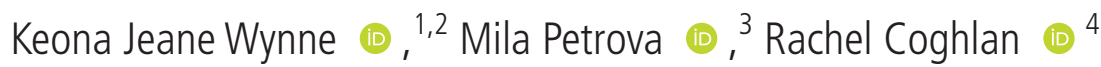

${ }^{1}$ Social and Behavioral Sciences, Harvard University T H Chan School of Public Health, Boston, Massachusetts, USA

${ }^{2}$ Center for Bioethics, Harvard Medical School, Boston, Massachusetts, USA

${ }^{3}$ Cambridge Palliative and End of Life Care Group, Primary

Care Unit, Department of Public Health and Primary Care, University of Cambridge, Cambridge, UK

${ }^{4}$ Centre for Humanitarian Leadership, Deakin University, Burwood, Victoria, Australia

\section{Correspondence to}

Keona Jeane Wynne, Social and Behavioral Sciences, Harvard University T H Chan School

of Public Health, Boston, MA 02115, USA:

kjwynne@g.harvard.edu

Received 5 November 2019

Revised 13 May 2020

Accepted 16 May 2020

Published Online First

19 June 2020

\section{ABSTRACT}

Background Humanitarian crises and emergencies, events often marked by high mortality, have until recently excluded palliative care - a specialty focusing on supporting people with serious or terminal illness or those nearing death. In the COVID-19 pandemic, palliative care has received unprecedented levels of societal attention. Unfortunately, this has not been enough to prevent patients dying alone, relatives not being able to say goodbye and palliative care being used instead of intensive care due to resource limitations. Yet global guidance was available. In 2018, the WHO released a guide on 'Integrating palliative care and symptom relief into the response to humanitarian emergencies and crises' - the first guidance on the topic by an international body.

Aims This paper argues that while a landmark document, the WHO guide took a narrowly clinical bioethics perspective and missed crucial moral dilemmas. We argue for adding a population-level bioethics lens, which draws forth complex moral dilemmas arising from the fact that groups having differential innate and acquired resources in the context of social and historical determinants of health. We discuss dilemmas concerning: limitations of material and human resources; patient prioritisation; euthanasia; and legacy inequalities, discrimination and power imbalances.

Implications In parts of the world where opportunity for preparation still exists, and as countries emerge from COVID-19, planners must consider care for the dying. Immediate steps to support better resolutions to ethical dilemmas of the provision of palliative care in humanitarian and emergency contexts will require honest debate; concerted research effort; and international, national and local ethical guidance.

\section{BACKGROUND}

Humanitarian crises and emergencies, events that are often marked by high mortality, have until recently excluded palliative care-a specialty focusing precisely on supporting people with serious or terminal illness or those nearing the end of life. Awareness of this paradox has recently been rising and a growing body of literature has been calling for the inclusion of palliative care into humanitarian and emergency responses. ${ }^{1-7}$ A seismic shift of attention is also happening now across all parts of the world-not only in pre-existing humanitarian crises-in the context of the COVID-19 pandemic. As of 9 May 2020, the International Association for Hospice and Palliative Care (IAHPC) lists over 145 'resources relevant to palliative care and COVID-19'. 8

Often unknowingly, this growing attention to palliative care revives the history of modern (Western) humanitarianism in emergency and crisis response. In one of the humanitarian sector's formative documents, Henry Dunant depicts the harrowing suffering he encountered in stumbling across the Battle of Solferino in 1859. ${ }^{9}$ Dunant suggested that compassionate care shown in accompanying and soothing the dying should be the foundation of humanitarian action.

In the $160+$ years since Dunant's experience, the capacity of both modern medicine and the broader humanitarian response to save lives has increased dramatically and continues to do so. Saving lives has become the paramount goal for both. Since the middle of the 20th century however, medicine has also evolved a branch specifically aimed at alleviating the suffering of those who cannot be cured and/or are dying. This is palliative care, which aims to prevent and relieve physical, emotional, social or spiritual suffering associated with any chronic or life-threatening illness and to promote dignity in suffering, death and dying. Humanitarianism and palliative care share both fundamental goals around easing suffering and upholding dignity, and a moral root in the recognition of our common suffering, fragility and humanity.

Powell et al suggest four types of humanitarian scenarios for which the provision of palliative care is especially relevant: (1) protracted conflicts where people endure life-limiting illnesses; (2) acute mass-casualty events where individuals are triaged based on likelihood to survive; (3) communicable disease outbreaks with limited therapeutic intervention options; and (4) within refugee and displaced persons camps. ${ }^{4}$ The ubiquity of such scenarios and benefits of palliative care to these populations demand the inclusion of palliative care within the humanitarian response.

At the time of editing this article, we are in the midst of the COVID-19 pandemic, an infectious disease caused by a newly discovered virus in the coronavirus family, for which there is currently no vaccine and no specific antiviral medicines. ${ }^{10}{ }^{11}$ As of today (27 May 2020), the data from the WHO are for 5451532 confirmed cases; 345752 confirmed deaths; and 217 countries, areas or territories with cases. From a palliative care perspective, this means that over 345, 800 COVID-19 deaths, each of the 
critical care cases, and many more unrecorded patients who are dying or have died with or without COVID-19 in the time of the pandemic, should have been considered for and typically offered palliative and end-of-life care. This is unlikely to be happening on such a large scale. Yet health systems across the world have had, for about a year and a half, clear guidance on the crucial importance of palliative care in humanitarian emergencies and the need to include palliative care in emergency preparedness. In September 2018, WHO released a guide on 'Integrating palliative care and symptom relief into the response to humanitarian emergencies and crises, ${ }^{12}$ - the very first guidance document on the topic by a pre-eminent international body.

The publication of the guide was a landmark moment for the field of palliative care in humanitarian settings. If governments, healthcare providers and humanitarian organisations have been swift to begin integrating its philosophy and practical recommendations in their planning, their efforts are likely to be rewarded in the current pandemic context. Yet a little over a year is almost as brief as the blink of an eye for the system transformation required, without the dramatic force of events as the ones we see unfolding. We are not aware of evidence of the guide's uptake in the aftermath of its publication, including in responses to COVID-19. Indeed, any reference to the guide or to palliative care are omitted from recent COVID-19 emergency and humanitarian response plans (eg, WHO's ${ }^{13}$ 'COVID-19 Operational Guidance for maintaining essential health services during an outbreak' and the UN Office for the Coordination of Humanitarian Affairs' ${ }^{14}$ 'Global Humanitarian Response Plan COVID-19'). We hope the guide's application has been far more widespread than the lack of references and formal evaluations may suggest, but this remains, for now, an open research question. And while no first major document of its kind could have withstood the challenge of COVID-19, we still need to scruitinise the guide for shortcomings and opportunities to improve on them and not only criticise the (likely) limitations of its uptake. Some of the guide's most important shortcomings concern, from our perspective, issues of ethics. This is the focus of our paper.

We argue that the WHO guide has employed, predominately, an ethical lens shaped by clinical bioethics, with its concern for the rights and well-being of individual patients and their interactions with healthcare providers. We propose that a future version of the guide will be dramatically enhanced in its ethical discussion by the incorporation of a population-level bioethics lens, among others. In a manner that is both contrasting and complementary to clinical bioethics, population-level bioethics focuses on the obligations of society to its members as individuals and groups. One of the fundamental contentions of population-level bioethics is that different segments or subgroups within a society will require varying 'right actions' due to differential access, availability and opportunity to use resources. ${ }^{15}{ }^{16}$ We suggest that palliative care has limited chances of becoming a recognised and integrated component of the humanitarian and emergency response unless we explore such obligations and the dilemmas associated with them.

We are also forced to explore those issues now. Many healthcare professionals, emergency services staff and humanitarian workers, as well as organisational leaders and policy-makers are shaken by powerlessness, guilt and fear from witnessing COVID-19 deaths which could have been avoided with better preparation; from being aware of the suffering and loneliness of those who are dying, while all available staff are needed to fight for the lives of those with higher chances of survival; or, with a growing likelihood, from contemplating decisions about withholding or withdrawing critical treatment because of severe resource limitations. They are grappling with what Slim calls 'hellish choices'. ${ }^{17}$ Doctors and ethicists across countries such as Italy, the USA, the UK and Australia have, expectedly, quickly seen the need to develop ethical guidance and decision-making frameworks to guide tough resource allocation and triage choices. ${ }^{18-23}$

We are living and witnessing harrowing experiences and tradeoffs relevant to palliative care on a daily basis, yet these dilemmas did not receive a mention in the WHO guide. Overall, the guide lacked a basic recognition of their existence, acuity and, potentially, ultimate irresolvability. And while we could not have imagined them easily on a global scale, they were painfully familiar to anyone who has worked in a humanitarian crisis or emergency. It is as if the issues we wanted to avoid by not thinking of the worst came back to haunt us.

Our analysis begins with a summary of the ethical discussion in the WHO guide. We then present briefly the distinct visual fields revealed by a clinical bioethics lens and a population-level bioethics lens. We describe in greater detail the population-level bioethics perspective, as it is relatively unfamiliar in the broader ethics community and often misperceived as a form of utilitarianism in a healthcare context. (To some degree, this may be an issue of nomenclature-the name of 'population-level bioethics' does not do justice to the key considerations underpinning the approach.) We argue that the pattern of representation of ethical issues in the WHO guide is consistent with over-reliance on a clinical bioethics lens. The core of the paper then outlines four sets of ethical concerns and dilemmas around the provision of palliative care in humanitarian emergencies and crises which become more visible once we expand our lens to think about who comprises the entirety of a population. These sets of concerns and dilemmas arise in relation to (1) rationing, (2) patient prioritisation, (3) euthanasia in the context of resource limitations and (4) legacy inequalities, discrimination and power imbalances. We conclude with suggestions on how to broaden the debate.

We offer neither in-depth articulation, nor resolutions to these concerns. Rather, we highlight the value of considering health as a social, cultural and historical phenomenon in addition to a biological one. The complexity of the issues deepens further when we consider the multiple social identities that intersect in the same members and groups within a population. We are confronted with ruefully complex, disturbing, even heartbreaking challenges. Yet until the COVID-19 pandemic, these challenges were not openly discussed in the context of palliative care-including in the WHO guide which is our main focuseven if they were a way of life for many humanitarian and emergency workers and intuitively sensed by individuals external to the sectors. And while satisfactory solutions may not be forthcoming for a long while, we can still debate more openly, think more critically and creatively, and take more of the little steps that allow us to act more compassionately and fairly. We may also acquire greater wisdom and humility, which tend to come with clearer awareness of our limitations in situations where normal life has crossed into chaos.

Though multifaceted and beyond the focus of our paper, it is important also to have some clarity on what defines or constitutes a humanitarian emergency or crisis. A situation is generally labelled a humanitarian emergency or crisis if international aid is required from donor governments or philanthropic organisations (the alternative is a local or national emergency); and where the humanitarian response comprises the formal system of local, national and international non-governmental organisations, United Nations bodies, the International Red Cross and 
Red Crescent Societies, military units and international disaster response teams. ${ }^{24}$

The types of emergencies and crises the formal and modern humanitarian sector is designed to respond to include conflicts, natural or man-made disasters, disease epidemics and the casualities and mass displacement that may be caused by any of these. Crises may be acute or chronic/protracted, and they may be sudden (such as an earthquake) or slow onset (such as a drought). A 'complex' humanitarian emergency is a more recent term to define those emergencies with multiple causes, and which destroy the integrity of whole societies and systems, requiring a system-wide response. Poorer countries constitute the majority of humanitarian crises, with their reduced capacity to prepare, respond and recover, although COVID-19 has necessitated an international response in some richer countries, for example, Medecins Sans Frontieres' (MSF)'s interventions in Italy, Spain and Belgium. ${ }^{25}$

It is our understanding that the WHO guide intends to speak to humanitarian health workers operating within this formal humanitarian system.

\section{CLINICAL BIOETHICS VIS-À-VIS POPULATION-LEVEL BIOETHICS}

Bioethics has always engaged with dilemmas at the level of both the individual clinical encounter and the health/illness experiences of populations and groups. Some topics, and palliative care is a case in point, reside simultaneously in both subfields. Clinical bioethics concerns itself with individual and patients' rights, whereas population-level bioethics includes consideration of the obligations of society to its members as individuals and groups. ${ }^{1516}$ This shifts the focus from 'the relationship and interactions of individual patients and their physicians' to the social determinants of health, including but not limited to, socioeconomic status, environmental and working conditions, and social exclusion. ${ }^{15}$ Clinical bioethics stipulates that a just outcome is obtained if an individual's needs are met, while population-level bioethics requires that the needs of the whole population are met. The broader scope of population-level bioethics allows for ethical analyses to consider the extent, direction and distribution of health resources, with special emphasis given to the least healthy populations. ${ }^{15}$

\section{POPULATION HEALTH}

The rise of population-level bioethics parallels the rise of population health sciences. The two are underpinned by shared theoretical assumptions about how the world works and how the world should work and the impact this has and will have on the health of populations, groups and individuals. It is thus helpful to consider the defining features of population health sciences in order to contextualise population-level bioethics.

The scholarly and practical field of 'Population Health' has its roots in traditional public health, but is, in many ways, a critical response to the latter's philosophical leanings. Valles traces its origin to a reaction against public health, with its heavily biomedical and, by extension, individual-centred approach. ${ }^{26}$ Population health has developed as a distinct alternative that 'is fundamentally concerned with the social structural nature of health influences, and, although it is embodied in the health outcomes experienced by specific individuals, the domains of influence that shape health experiences transcend the characteristics or circumstances of any one individual'. ${ }^{27}$

The biomedical model situates disease and its causes solely within biological, chemical and physical phenomena. It is characterised by a philosophical and methodological reductionism that espouses that the sum is best explained by the parts. Such a perspective leads to public health interventions aimed at 'prioritising the development and distribution of drugs and devices that can 'fix' any broken tissue'. ${ }^{26} 28$ Intellectual and material resources are disproportionately allocated towards medical interventions as opposed to policies and health interventions that would address the social determinants of health.

Philosophically, the practice of biomedicine, which relies heavily on the biomedical model, finds its primary underpinnings in deontology; that is, the duty one person has in relation to another in a specific situation. Ideally, this does not mean that there is little regard for the good of the population. In practice, however, the good of society is often secondary to the care and advocacy for a specific patient. ${ }^{29}$ This narrow conceptualisation of deontology translates well in the context of individual clinical encounters but fails in areas of work focused on the entire population. A broader application of the deontological model, one that assumes that populations should operate based on rules and intent, still falls short of the needs of ethical decisionmaking about population health. Rules are stringent and inflexible. Alone, deontology does not allow sufficient room for the tradeoffs that must be considered to maintain population health.

The biomedical model is also compatible with a utilitarian framework. Within the latter, the goal of public health is to achieve the 'good' for the majority of the individuals within a population. Indeed, bioethicists have argued that it is utilitarian justifications that underlie public health interventions, more specifically, paternalistic interventions aimed at altering behaviour to maximise the overall good. ${ }^{30}{ }^{31}$ Utilitarian principles are frequently considered the most rational and intuitively 'right' at the level of population health, even if acknowledged as hard, potentially excruciatingly so, to apply vis-à-vis the specific individuals whose well-being or lives are sacrificed in their application. Less conspicuously, utilitarianism operates under the assumption that the health of the population is simply the sum of the health of its individuals, with no consideration for the impact of, for instance, cultural and societal history, power dynamics or social status. If health is socially patterned, and there is overwhelming evidence that it is, we should expect unjust differences in health among subgroups based on social identity (eg, race, gender, nationality, etc) and work to eliminate these differences. A utilitarian framework that prioritises the 'utility' or 'health of the majority' may do very little to eliminate health disparities.

The goal of population health is to reduce and eliminate health-related gaps between groups. As a result, the discipline does not concern itself with either individual 'duties' or overall utility but with equity. The inclusion of equity mandates that particular attention is paid to the importance of individual, familial, cultural and societal history, as each of them separately and all of them together can result in different 'starting points'. The focus is on health and on social, environmental and biological factors that influence health as opposed to healthcare (care for the ill). Additionally, as 'individual health and population health dynamically and mutually affect each other over a gradual passage of time', ${ }^{26} 32$ the shifts of focus from individuals to populations and vice versa are a key analytical pattern. Unlike traditional paternalistic public health, population health also advocates for unprecedented multidisciplinary and cross-sector collaboration. Importantly, the weight it gives to the lived experiences and resources of citizens and communities is on a par with that given to scholars or organisations. 
Table 1 Population-level bioethics in comparison to deontology and utiliarianism

\begin{tabular}{|c|c|c|c|}
\hline & $\begin{array}{l}\text { Deontology } \\
\text { (moral framework) }\end{array}$ & $\begin{array}{l}\text { Utilitarianism } \\
\text { (moral framework) }\end{array}$ & $\begin{array}{l}\text { Population-level bioethics } \\
\text { (guiding questions to moral dilemmas) }\end{array}$ \\
\hline Core concept & Duty to the individual & Maximising utility & Equity within the population \\
\hline Right action & $\begin{array}{l}\text { Respect the rights and needs of all } \\
\text { persons in the populations }\end{array}$ & $\begin{array}{l}\text { Maximise the greatest good for the } \\
\text { greatest number }\end{array}$ & $\begin{array}{l}\text { Determine the appropriate tradeoff between } \\
\text { populations }\end{array}$ \\
\hline Strengths & All persons are respected & A large amount of good is produced & $\begin{array}{l}\text { Considers innate and acquired differences } \\
\text { between groups \& subgroups }\end{array}$ \\
\hline Limitations & $\begin{array}{l}\text { There is no consideration of the } \\
\text { population }\end{array}$ & $\begin{array}{l}\text { There are no resources provided for the } \\
\text { 'minority' groups }\end{array}$ & $\begin{array}{l}\text { It is difficult to determine how much of each } \\
\text { resource to provide to each group }\end{array}$ \\
\hline
\end{tabular}

\section{POPULATION-LEVEL BIOETHICS}

Population health arguments typically revolve around a complex tension between two groups, for instance, high-risk versus low-risk, oppressed versus privileged, high-income versus lowincome groups. Population health also acknowledges that, within a population, subgroups may require different resources for equity to be achieved, as subgroups too may be starting from vastly unequal innate and acquired resources. In light of the above, the goal of population-level bioethics can be construed as to investigate tensions between and within populations which result in inequitable health outcomes, and to uncover ethical solutions to health-related challenges which are equitable to all members of the population.

Unlike deontology or utilitarianism, population-level bioethics is not a moral framework, which prescribes the right type of action to be carried out. Rather, it is a set of guiding questions and considerations that support actors in engaging critically with the health tradeoffs inherent in any society. These questions and considerations only become apparent when we take a perspective which allows us to identify previously unseen tensions between groups. Once such a tension is pinpointed, a deontological or consequentialist (utilitarian) approach can be used to explain or rectify disparities between the groups that comprise the population. The 'right action' can then be, for instance, the implementation of structures and processes that eliminatein the short, medium and long terms-as many unjust health disparities between groups as possible. A distinguishing feature of population-level bioethics is that it does not stipulate that all persons within a population are subject to the constraints of a specific moral framework. Rather, within a population, multiple moral frameworks may need to be applied simultaneously to achieve fairness. An additional requirement of population-level bioethics is thus to recognise and at times harmonise conflicting moral frameworks so that they may work together for the good of population health. Table 1 represents schematically the standing of population-level bioethics relative to deontology and utilitarianism.

\section{Bioethical issues in the WHO guide and the broader literature it could draw on}

In the WHO guide, ethical issues are approached in a principlist fashion, consistent with a clinical bioethics framework. The seven principles addressed in it and the particular ways in which they are conceptualised are summarised in table 2. The guide also devotes a brief section to issues around 'ethics and culture', namely matters of unconscious biases, cultural values,

Table 2 Ethical principles that should guide palliative care and symptom control in humanitarian contexts, as per WHO 2018 guide

\begin{tabular}{ll}
\hline Ethical principle & WHO guidance \\
\hline Respect for persons & All patients' dignity and human rights must be respected. \\
& Health professionals should provide patients with all health-related information, respect their decision-making and provide appropriate \\
Non-maleficence & Peatient's health-related information should remain confidential. \\
& All patients should have access to palliative care to minimise suffering. Expectant patients should only receive palliation. \\
& Avoid complicity with torture (political ethics?) \\
Beneficence & Work to provide the patient with the most good by meeting their physical, psychological, social and/or spiritual needs. \\
& Anticipate and prevent future suffering. \\
Justice & Show great judiciousness when the good of the patient or family may be in conflict with the public good (eg, infectious diseases). \\
& Sulnerable patients may require more intensive services. \\
& Health providers and aid workers may require increased health services due to added risks and burdens (principle of reciprocity). \\
Solidarity & A community, including the global community, should stand together to face common threats and overcome pathogenic inequalities. (political \\
& ethics?) \\
Non-abandonment & Medical care should be provided to all needy patients. \\
Double effect & An action intended to bring about a good outcome (alleviation of pain) is permissible despite the possibility of a harmful outcome (hastening death). \\
& The reason for undertaking such high-risk action must be grave (misuses of science?). \\
\hline
\end{tabular}


stereotyping and human rights. ${ }^{12}$ To address clashes of prima facie duties or 'when there are two or more conflicting moral imperatives, neither of which takes clear precedence, and when obeying one imperative would result in transgressing another', the guide recommends (1) inclusiveness (2) communication (3) transparency (4) accountability (5) consistency and (6) ensuring comfort. ${ }^{12}$ Finally, although the word 'euthanasia' is never explicitly mentioned, brief references in chapters 3 and 7 are made to 'hastening death' as unintentional, be it potentially foreseeable, outcome of attempts to ensure comfort in cases of 'severe, refractory symptoms in a patient with a terminal illness or mortal injury'. ${ }^{12}$

Table 2 summarises the ethical principles advanced by the WHO guide. ${ }^{12}$ Bullet points in bold and italics represent principles underpinned by an implicit concern for groups and populations. 'Normal' sentences represent principles that are solely clinical in nature (concerning the care for individual patients). Principles in bold are consistent with a population-level bioethics lens. Principles which seem to fall outside of both these frameworks are annotated with a question mark and a conjecture of the most proximate ethical debate, not least in view of the political context in which the guide was prepared (eg, political ethics?).

Four of the seven principles advanced by the guide-respect for persons, non-maleficence, beneficence and non-abandonmentare conceptualised partly with a clear focus on individual patients and individual clinical encounters, partly with a reference to a generic 'all'. The latter inclusion of the entirety of a population, however, remains at this minimalist level, as if the complexity created by that 'all' can be fully resolved through the rules pertaining to the 'one'. No attention is given, for instance, to potential tensions between the needs of individual patients, as arising from resource limitations and/or other socioeconomic and historical determinants of health.

Two of the remaining principles, justice and solidarity, are likely to require attention to population-level issues, as the presence of 'others' is an implicit or explicit element of their definitions (and those others will often belong to groups or subgroups, as per the concerns of population-level bioethics). Yet the principle of solidarity is only couched in terms of a community, including the global community, facing threats together and taking a stance against inequalities. The principle of justice is specified mostly in terms of non-discrimination and priority treatment based on need, with no recognition for the sometimes insurmountable challenges their practice may encounter, as arising from systemic socioeconomic issues or resource constraints. Finally, while the principle of double effect is framed in a generic way, it is specified through examples which focus on palliative care for individual patients.

The limitations of the ethical debate in the WHO guide were, perhaps, a direct consequence of the limitations of the broader literature it could draw on at the time of its writing. While texts on palliative care in humanitarian contexts which also raise ethical issues and tensions are, in the current COVID-19 context, multiplying daily (for a collection, see, for instance, Ref. 33), this was a severely underexplored topic before the current pandemic. Previously, the state of the ethical debate on palliative care in humanitarian contexts was most prominently covered in a section of a broader systematic review by Nouvet et al. ${ }^{34}$ The articles examined in the review raised issues around care for terminal patients, vulnerable populations, moral distress among providers, euthanasia and the tension between allocating resources for salvageable and nonsalvageable patients. ${ }^{34}$
A number of stakeholders had been stepping in to fill this void even before the COVID-19 pandemic. For instance, ELRHA ( elrha.org), a global charity 'that funds solutions to complex humanitarian problems through research and innovation' funded a project by the Humanitarian Health Ethics team-a multidisciplinary research team led by researchers at McMaster and McGill Universities- to 'develop evidence clarifying ethical and practical possibilities, challenges, and consequences' faced by humanitarian organisations in the provision of palliative care and then create relevant guidance on the basis of it. ${ }^{35}$ Palliative Care in Humanitarian Aid Situations and Emergencies (PalCHASE), a network serving as the current focal point for advocacy and debate about palliative care in humanitarian contexts, has also been committed to elucidating associated ethical issues. ${ }^{36}$ Yet many of the above initiatives were only just underway, with their evidence and guidance still forthcoming.

The COVID-19 pandemic has triggered new levels of critical thinking and associated solutions around ethical issues and the place of palliative care, as least in rich country contexts. Yet the specifics of pre-existing humanitarian contexts have hardly been addressed. Much of the ethical debate which at some stage involves palliative care is focused on rationing and allocation of critical treatments such as ventilators and intensive care bedsunlikely considerations in many parts of the world where such high-cost treatments are not available.

In what follows, we aim to contribute to this scarce but rapidly evolving debate by taking a population-level bioethics perspective and addressing issues of rationing; patient prioritisation; euthanasia in the context of resource limitations; and legacy inequalities, discrimination and power imbalances.

\section{WHAT ARE THE POPULATION-LEVEL CONCERNS? Limitations of human and material resources}

When considering the equitable access to palliative care across the many different subgroups which comprise a population, we need to take into account the pre-existing resources available within a society as a whole. On the one hand, this defines what is equitable, while being achievable enough, within a particular society. On the other hand, it brings to the fore inequalities and injustice across societies that need to be addressed at a higher level. A framework of 'stuff' (medication, equipment), 'staff', 'space' and 'systems ${ }^{37-39}$ has gained popularity in describing resource needs for palliative care during an emergency. Here, we focus on resource limitations concerning stuff and staff. We first consider them at a broad societal/population level (against the background of expectations in the WHO guide), before looking into the implications such resource limitations have for tradeoffs between groups and subgroups within a population.

The WHO guide recommends that palliative care services, with a specific emphasis on the provision of medication for pain relief and symptom control, be made available to everyone who may need them in humanitarian emergencies and crises, regardless of triage status. ${ }^{12}$ Since WHO declared the COVID-19 outbreak a global pandemic (11 March 2020) ${ }^{40}$ even some high-income countries have experienced or are experiencing drug shortages. Palliative care drugs are also used in intensive care units (ICU). Competition for these drugs has been reported as one of the reasons for a change of palliative care plans in a Swiss hospital near Northern Italy. ${ }^{41}$ Shortages of sedatives and drugs for the management of breathlessness have been commonly reported in the USA. ${ }^{42}$ The search for creative solutions, not devoid of other agendas, has even led to appeals to US death penalty states to release medications stockpiled in correctional facilities. ${ }^{43}$ Even 
when no country-level drug shortages have been apparent (eg, in Germany), national authorities have issued guidance against stockpiling ${ }^{44}$ to avoid the risk of shortages arising in some parts of the system from overpreparation in other parts of it. In a global supply chain, loss of drug production capacity in certain countries (as in China or Italy in the current crisis), trade wars and national bans aimed at ensuring supply for one's own citizens $^{42}$ can further limit the availability of drugs-for palliative care as for any other type of need-at critical timepoints.

In the previous infectious disease crisis parts of the world where citizens have endured (and continue to endure), the Ebola epidemic, the lack of morphine for pain relief has been well documented. ${ }^{45}$ The lesson seems to be currently repeated though, arguably, in part because Ebola has not wreaked havoc on the developed world. The COVID-19 pandemic may imprint such drug shortages in new and powerful ways on a global scale. The ambition of providing medication for pain relief and symptom control to everyone who may need them in humanitarian emergencies and crises is, however, up against vast inequalities in palliative care globally, as argued for persuasively in a 2018 Lancet Commission report. ${ }^{5}$ The need for improvement is particularly acute in low-income countries. ${ }^{5}$ Between the years 2010-2013, only $0.03 \%$ (0.1 out of 298.5 metric tons) of morphine-equivalent opioids were distributed in lowincome settings. ${ }^{5}$ Some of the key factors contributing to such gross global inequalities and unmet need are deep seated and/ or emotionally charged, such as unwarranted attitudes towards medically indicated opioid use; inequity in the global pricing of opioids; and advocacy limitations, since terminal patients can hardly engage in relevant activity. ${ }^{5}$ The COVID-19 crisis may facilitate future efforts towards removing such roadblocks and improving palliative care services in parts of the world where these are hardly available. But it may also push palliative care further down the list of priorities.

For instance, is providing short-term to long-term pain management and comfort care the best way to spend limited funds in humanitarian contexts, where even the basics of survival may be under threat? Pain management drugs are inexpensive, as also emphasised by the WHO guide, yet in a resource-scarce environment, where critical priorities are pitched against one another, more money for drugs may still mean less money for housing, food, clean water and sanitation facilities. Moreover, the health professionals who can appropriately prescribe and administer those drugs are not an inexpensive resource. A utilitarian standpoint would support this challenge against palliative care advocates, given that providing adequate nutrition to sustain life, sanitation facilities and clean water to prevent the transmission of communicable disease, and housing to protect individuals from the natural environment will increase population health. This tension is not at all theoretical: unmet needs for food, water, sanitation and hygiene in humanitarian contexts are well documented. ${ }^{46}{ }^{47}$ Even practitioners and staunch supporters of palliative care (as we, in fact, are) may find it hard to argue for pain relief versus bread/rice or water. Asserting that we must do our best to meet all those needs does not make the current real-life decisions of funding allocation any less acute.

A further question around the (non-specialist) staff who may be expected to deliver palliative care also arises. The physicians and various healthcare professionals of modern medicine believe that, above all, the purpose of their work is to cure. ${ }^{48} \mathrm{In}$ a medical context, death is typically viewed as a failure. Modern biomedicine also seems to be driven by a hubris that it is exclusively dedicated to survival, making the alleviation of suffering 'someone else's problem'. ${ }^{49}$ While the unquestioned supremacy of such beliefs needs to be challenged in medical education and healthcare as a whole, we need to work from the fact that most health professionals who are in active practice now, including those working in humanitarian crises or hospital emergency and critical care settings, are trained within similar sets of beliefs. The requirement for the provision of palliative care may then exacerbate the moral distress already prevalent in non-palliative healthcare workers, by imposing a responsibility that conflicts with their reason for being in the field. Indeed, some of the most heart-breaking personal stories emerging from the COVID-19 pandemic are those of emergency care clinicians who have chosen their field of work 'to save lives' and are now losing 'battle after battle' like never before. ${ }^{19}{ }^{50-52}$ There is also broader evidence that health providers may feel useless if unable to cure patients. ${ }^{48}$ Moreover, the boundaries between medical specialties in humanitarian settings and emergencies are far less enforceable. Healthcare workers may be reallocated from their specialities ${ }^{41}$ and expected to provide palliative care without prior experience and appropriate training. There will be numerous situations where the palliative care team cannot be 'just called in'-and especially so in pre-existing humanitarian crises. The authors of the guide recognise that healthcare workers may experience 'helplessness and distress' due to an inability to alleviate suffering. ${ }^{12}$ They also cite 'overworking, overwhelming emotional exposure, hardship in the field, lack of self-care and poor personal management' as reasons for humanitarian workers' burnout. ${ }^{12}$ However, they do not consider the possibility that the two might reinforce each other when palliative care services begin to be incorporated in the humanitarian and public health emergency response.

\section{Who to prioritise?}

The WHO guide recognises that essential palliative care drugs such as morphine are scarce in humanitarian situations. ${ }^{12}$ It too includes the lack of morphine during the Ebola outbreak of $2014-2015^{45}$ as an example of that scarcity. Yet the authors seem to consider this a state of affairs that can easily be changed, since the legal basis is there-namely, the exceptions in international drug laws that govern the import and export of narcotics during emergencies. ${ }^{12}$

Historically, the baseline amount of global narcotics is quite low. ${ }^{5}$ As the above examples of drug shortages and some of their explanations (such as competition with ICU needs or loss of drug production capacity in key country producers) have begun to demonstrate, even high-income countries may struggle to achieve adequate supply. Even if improvements in baseline availability and preparedness happen with phenomenal efficiency, there will be transition periods and contexts where pain medications are, indeed, a scarce resource. How should pain medications be prioritised then and to whom ${ }^{2}$ ?

In the WHO guide, palliative care is all encompassing. It is provided to patients regardless of triage status. However, when resources are scarce, it is inevitable to categorise patients and limit care to only some categories of these. When it comes to any form of life and death situation handled with limited resources, the primary dimension of categorisation is uncompromisingly clear: those who will survive and those who will not.

Using the principles provided by the guide, there is no clear answer whom to prioritise for palliative care. Victims of emergencies with non-survivable diseases and injuries may take days to weeks to expire. ${ }^{12}$ Is it right to continuously provide such patients with pain medication and comfort care while depriving of these patients who may survive? Or, should we allocate all pain medications and personnel towards those who are likely to survive in order to increase their current and subsequent quality 
of life? The authors of the guide are adamant that palliative care is second only to life-sustaining measures. ${ }^{12}$ Based on this logic, if human and material resources are scarce, those patients triaged as expectant will not be allocated palliative care resources in order to maximise the quality life years or utility for individuals for whom curative interventions are an option. This conclusion is contrary to the ethical and human imperative to provide care to all patients and practically leads us, full circle, to the point which spurred the movement for palliative care in humanitarian settings in the first place.

The authors of the guide do, indeed, state often that society is morally obligated to provide palliative services to expectant patients. In chapter 6 , they remark on the 'false dichotomy' between patients capable and not capable of being saved, ${ }^{53}$ insisting that both can receive active healthcare even in situations where resources are overwhelmed. ${ }^{12}$ This dichotomy only becomes false if one works under the assumption that resources, even when overwhelmed, are not scarce. Such an assumption is not supported by historical and emerging COVID-related evidence. We agree that there is a moral duty to provide palliative care to all patients, especially those for whom life-saving interventions are withheld due to scare resources. But the WHO guide lacks practical guidance on how to distribute this care, and what constitutes a minimum level of care where severe resource constraints exist.

Finally, the provision of palliative care in humanitarian crises adds a new dimension to the potential conflict between health worker safety and duty of care (non-abandonment). ${ }^{1}$ The case of Memorial Medical Center in New Orleans, Louisiana, provides an example of how quickly and unexpectedly dilemmas around health worker safety and patient abandonment may arise. During Hurricane Katrina, Memorial Medical Center encountered extreme difficulties in evacuating patients. ${ }^{54}$ There were too many people (patients and healthcare workers) and not enough helicopters to transport them. ${ }^{54}$ A decision on prioritisation had to be made. It was that the sickest patients and those with Do Not Resuscitate orders were to be evacuated last. Regardless of whether we agree with this particular decision or not, we must acknowledge that there are crisis situations when decisions about whom to save and whom to abandon need to be made in minutes, even split seconds, without opportunities for careful deliberation or consulting an ethics committee. In the current COVID-19 pandemic, the dilemma around balancing healthcare worker safety against the duty of care in a palliative care context has reappeared in the care homes of several countries (eg, Italy, Spain, France, UK). Staff in many care homes have not had sufficient personal protective equipment to allow them to care safely for patients dying with COVID-19. The challenge has been further exacerbated by understaffing due to carers becoming infected and going into quarantine, overlaid onto chronic staff shortages in the sector. ${ }^{55-57}$

As the current pandemic has grown, international aid workers operating in existing humanitarian crises too have been forced to make the impossible decision to stay and deliver much needed assistance to communities; or to leave their positions-and the communities they serve-to avoid confinement, the possibility of facing health risks away from their own families, or not being able to reach family members who may fall ill amidst a world in lockdown. Either choice has led to distress for many humanitarian workers. Even staying to fulfil the humanitarian imperative brings with it risks of 'doing harm' to communities by spreading the virus. ${ }^{58}$

How much should healthcare workers risk their own safety so as to leave no-one behind and/or accompany the dying? Should they risk dying themselves in order to relocate to a safer place patients who are already dying or accompany infectious disease patients in their final hours? If some of those who are dying will be left behind or left alone, what is the right thing to do for them? How do the ethos and practice of palliative care interact with these questions?

\section{Euthanasia, assisted suicide and assisted dying}

This brings us to the highly controversial topic of euthanasia, assisted suicide and assisted dying; and the standing, in humanitarian emergencies and crises, of the individuals and groups who may be contemplating such an end to their lives, whether legal or illegal in a particular jurisdiction. Euthanasia translates, from Greek, as 'good death'. ${ }^{59}$ Euthanasia and the closely associated phenomena of assisted suicide and assisted dying have an ambiguous relationship to palliative care. In lay understandings, they are not only closely associated, but not infrequently misperceived as aspects of palliative care. At the same time, particularly in countries where euthanasia is illegal, they can be seen as antithetical. ${ }^{60}$ A 2017 study of 62 declarations on euthanasia/assisted dying by Inbadas et al found all 13 declarations of palliative care organisations to take a position 'against' (with emphasis on clarifications that a patient's refusal or stopping of treatment, the withdrawal of futile treatment and palliative sedation are not forms of euthanasia). ${ }^{61}$ Briefly, the argument is that people would not seek euthanasia if they are provided with good palliative care. Most recently (2016), the IAHPC has stated that no country should consider the legalisation of euthanasia or physician-assisted suicide until it ensures universal access to palliative care services and to appropriate medications, including opioids for pain and dyspnoea. ${ }^{62}$

Conversations surrounding euthanasia can easily become convoluted. For the purposes of our discussion, we will only focus on how euthanasia interacts with the moral predicaments around resource limitations and patient prioritisation we have addressed so far. We will consider both voluntary and non-voluntary euthanasia, one of the most widespread typologies of euthanasia. Voluntary euthanasia is 'where a person makes a conscious decision to die and asks for help to do so', while in non-voluntary euthanasia 'a person is unable to give their consent to treatment (eg, because they are in a coma) and another person takes the decision on their behalf, often because the ill person previously expressed a wish for their life to be ended in such circumstances'. ${ }^{63}$ We will also circumscribe the debate by highlighting that euthanasia is not permissible under international humanitarian law. ${ }^{64}$ This makes the debate legally theoretical, yet no less acute.

In resource-scarce environments, is the right thing to do only to relieve pain? ${ }^{3}$ Is there a role in such contexts for voluntary or non-voluntary euthanasia and/or assisted suicide to alleviate intractable pain, conserve pain medications and reduce the emotional burden on care providers and loved ones, ${ }^{23}$ while also respecting patient wishes?

The WHO guide never explicitly uses the word euthanasia but does endorse providing medication to relieve severe, intractable pain, even if a side and unintentional effect of this may be to 'hasten death'. ${ }^{12}$ The intention behind such acts may be the only-and hidden-component which distinguishes them from some forms of euthanasia. The conversation about euthanasia thus hovers above the guide and seems to have deserved direct mention in it.

One of the most controversial aspects of that conversation is that, in humanitarian contexts, arguments around the mercy in euthanasia are (perceived to be) entangled with considerations 
around resource limitations. As discussed, expectant patients may take weeks to days to expire. ${ }^{12}$ Providing patients with a single, larger dose of barbiturates to enact a decision about euthanasia as opposed to administering small doses to achieve pain relief, over an extended period of time, can conserve medication. This medication can then be made available to others in need, who may not have been prioritised up to that point. While such dilemmas may be prime examples of 'hellish choices', it seems a given that some health professionals and some victims of disasters, no matter how few, have had to face such choices in all their brutality.

Yet even if a health professional has grappled with such dilemmas in their humanitarian work, as a rule, they would not have ever spoken about them. There are only a few countries (Belgium, Canada, Luxembourg, the Netherlands and Switzerland, Colombia) and a handful of US states and more recently Australian states (California, Colorado, Montana, Oregon, Vermont and Washington, New Jersey, and Hawaii in the USA; and Victoria and Western Australia in Australia) that have legalised euthanasia or assisted dying. ${ }^{65}$ As mentioned, euthanasia is not permissible under international humanitarian law.

It could be argued that there are conversations to be had of whether the reference points relative to which societies decide on the acceptability and morality of euthanasia still hold fast in extreme humanitarian emergencies and crises, where suffering can take unimaginable proportions. These might also be contexts which demand of palliative care practitioners who are firmly opposed to euthanasia under normal life circumstances to further, or even reconsider, their argumentation.

We do not argue for or against euthanasia. We argue that profound unintended negative consequences may follow if we downplay the likelihood that euthanasia-related concerns and dilemmas may arise in new ways for both humanitarians and palliative care practitioners once we begin to integrate consistently palliative care into the response to humanitarian emergencies and crises. These are likely to be further exacerbated for some expatriate humanitarian workers who, on one hand, may be influenced by vastly different beliefs about autonomy and choice in decisions about death and dying than those of local populations and, on the other, will often have no shared language to discuss or decline to discuss such topics.

\section{Legacy inequalities, discrimination and power imbalances}

This brings us to our final critique. Palliative care is not provided in a vacuum absent of social, economic, geographical, historical, political, cultural and similar interrelated forces, associated with gross inequalities and sources of conflict. If anything, the interplay of these forces is often the very cause of complex humanitarian crises.

An article subsection only permits sketchy examples of how such factors may interact with the provision of palliative care in humanitarian emergencies and crises. But we hope that the ones we offer can illustrate how, if initiated incorrectly, palliative care services can inflame deep wounds, aggravating already perilous and precarious situations.

To begin with issues of discrimination, there are at least two lines of argument suggesting that we need thoughtful plans to limit discrimination in palliative care in humanitarian contexts, as opposed to broad assertions that we are committed to it not happening. The first stems from discrimination in pre-existing humanitarian contexts; the second from discrimination in palliative care in 'normal life' and in the developed world. In turn, discrimination can take the form of both lack of provision of palliative care for traditionally discriminated groups or provision of palliative care instead of curative care when the latter is available but limited.

Some discrimination may even be (tacitly) endorsed, both in palliative care and humanitarian settings. Such is the case of age. The impulse is often encapsulated in the 'fair innings' argument: older people have already lived enough on this planet; the younger ones have not had the chance. A 36-member US-based Steering Committee named The Pediatric Emergency Mass Critical Care Task Force remarks (and endorses) that 'if several children can be saved with the resources used to treat one then it is ethically appropriate to favor several over one' ${ }^{66}$ The omission of who the resources are to be taken from creates significant ambiguity, but it is unclear why, if the implied 'one' were not an adult, the statement would be worth making: prioritising the lives of several children over that of a single child would be a standard utilitarian choice, where no matter how excruciatingly difficult the sacrifice is and how many different solutions we attempt before resorting to it, the right thing to do would be hardly debatable, at least in the absence of further considerations. Furthermore, the Task Force remarks on the 'unique attributes' of children, citing increased body surface area-tomass ratio, decreased subcutaneous tissue, decreased herd immunity and decreased cognitive development as reasons children may be categorised as a vulnerable population ${ }^{66}$ and, therefore, deserving of special priority. What these authors do not say is that the inclusion of such factors in a triage system will result in children always being prioritised for curative interventions over many adults in humanitarian crises.

We have seen the operationalisation of the fair innings argument play out in practice in the current pandemic. The health system in Italy, overwhelmed beyond capacity, 'invoked' the argument to justify prioritising younger adults for intensive care services over older, sicker adults. ${ }^{18}{ }^{67}$ While we may promote cultures of non-discrimination-and we generally accept that we would not discriminate based on gender, age, ethnicity or disability-pandemic triage decisions are, by their nature, broadly discriminatory. Even ethical decision-making frameworks currently being developed or used which invoke characteristics other than age, such as quality of life or maximising quantity of life years saved, frequently converge around the exclusion of older people. ${ }^{18}$

The empirical evidence on the deprioritisation of older people in humanitarian crises is compelling. During Hurricane Katrina in New Orleans, Louisiana, $75 \%$ of the deaths were of individuals over the age of 60 , despite the latter accounting for only $16 \%$ of the overall population. ${ }^{68}$ In Japan during the 2011 tsunami, $56 \%$ of the deaths were of individuals aged 65 and above, despite their accounting for only $23 \%$ of the local population. ${ }^{68}$ The disproportionate deaths among older people need not be due to explicit discrimination in triage mechanisms. ${ }^{67}$ Most humanitarian policies pay lip service to, or do not account at all for, the unique needs of this vulnerable population, for example, through policies addressing transportation to care facilities, nutrition and family separation. ${ }^{68}$

With racial discrimination, there is clear evidence of it occurring both in normal times within the developed world, and during times of humanitarian crisis. The mechanisms may be circuitous. During Hurricane Katrina, residents of New Orleans were urged to evacuate by car before the hurricane made landfall. ${ }^{69}$ However, Black Americans, who, at the time, made up $46 \%$ of the population of the city, were over three times more likely not to have access to a vehicle, leaving them vulnerable to disproportionate morbidity and mortality. ${ }^{69}$ In the USA, people of African and Latin descent are routinely undertreated 
for pain ${ }^{70-72}$ and their end-of-life wishes are assumed based on cultural generalisations. ${ }^{73}$ In the UK, a study revealed that Black Caribbeans were less likely to be aware of palliative care as a specialty than their White British counterparts ${ }^{74}$-an example of how structural discrimination can impede equity even before a disaster strikes.

There are pre-existing barriers when minority and vulnerable populations attempt to access either humanitarian support or palliative care as well as inequalities in their provision. At the intersection of the two, challenges are at best likely to be replicated and, potentially, significantly augmented. Again, COVID-19 has exemplified how a humanitarian crisis can expose pre-existing discrimination and structural racism. In the USA (as of 18 April), Black Americans accounted for 33\% of COVID-19 hospitalisations and 34\% of deaths (in 26/50 reporting states). ${ }^{75}{ }^{76}$ In the UK, a report of the Institute for Fiscal Studies (May 2020; the pandemic still ongoing) estimated that 'Bangladeshi hospital fatalities are twice those of the white British group, Pakistani deaths are 2.9 times as high and black African deaths 3.7 times as high'. ${ }^{77}$ Such stark inequities have even prompted US ethicists, to ask if White Americans should be deprioritised for critical care services to prevent the structural racism which grants them these life-saving privileges while depriving others. ${ }^{78}$

Ethnic minority populations are disproportionately marginalised to low-income jobs where exposure to infectious diseases is more likely; and to poorer diets and poorly constructed built environments that are often risk factors for chronic illnesses such as diabetes, obesity and hypertension. In turn, emergent COVID-19 triage and ethical guidelines for critical care services in scarce resource environments deprioritise on the basis of pre-existing conditions, ${ }^{79-81}$ thus further increasing the likelihood that racial and ethnic minorities suffer a higher death toll than the dominant group. If some of the above guidelines are also followed in their otherwise commendable emphasis on providing symptom control and palliative care to patients who have been deprioritised for critical care, then minorities may become overexposed to palliative care as a direct consequence of resource limitations. This would not be any 'fault' of palliative care and its practitioners. The deprioritisation decision too may be genuinely clinical, with no relationship to ethnicity at the point of patient presentation. But the legacy inequality and discrimination based on race and ethnicity will be underpinning the outcomes, and palliative care will be implicated in them.

Challenges such as the above are also likely to be amplified in middle-income and low-income countries. Poor infrastructure, greater disease burden and fewer resources, reflecting the inequitable global distribution of wealth, contribute to higher mortality after an emergency. ${ }^{12}$ These also have an impact on the timeliness with which people can access services, which, in turn, has implications for the availability of treatments. If curative interventions are dispersed on a first-come, first-serve basis, once depleted, palliative care services may be the only intervention available. Members of populations who faced barriers to arriving first for care may be relegated to palliative services not because of medical indication but, rather, because of social identity. Palliative care may thus become a tool for masking and perpetuating inequity. How can we ensure that implicit biases or structural forces such as socioeconomic status do not impede appropriate care, whether curative or palliative, for minority or vulnerable populations in humanitarian contexts? ${ }^{82}$

We should also recognise that many middle-income and lowincome countries were once colonised by many of the same countries which provide aid today. ${ }^{83}$ In light of global colonialism, what does it look like for respondents from predominantly high-income countries to provide palliative care to persons from middle-income and low-income countries? We cannot assume we have earned the trust of these countries and communities and that all stakeholders will believe that endeavours of palliative care are pure hearted and not, indeed, extermination.

During the Ebola epidemic in Sierra Leone, for instance, local people were hiding corpses because they believed that the aid workers were selling the organs of their loved ones. ${ }^{84} 85$ There again, there were rumours that Water, Sanitation and Hygiene teams were poisoning the water when they were chlorinating it; that drug companies were bringing in a disease for which they would then offer an expensive cure; that it was the nongovernmental organization (NGO) workers who were infected with and spreading Ebola; and that, overall, 'the white man only turns up when people die, so there must be a link' (personal communication from I Jacklin, 2019). More currently, public health experts speculate that the Ebola outbreak in the Democratic Republic of Congo, which is reported as the world's second-worst outbreak, is being fuelled by mistrust and 'community scepticism' ${ }^{86}$ It has been reported that 74 Ebola treatment centres were attacked due to such mistrust and beliefs that the continued Ebola outbreaks are profit driven ${ }^{86}$ (eg, white countries profiting from the illness and death of black bodies). In the current pandemic, UN aid workers have been blamed for bringing COVID-19 to South Sudan after four of its staff tested positive, triggering xenophobia and the suspension of aid activities, and fuelling existing political suspicion over the presence of the UN in the country as interfering with sovereignty. ${ }^{87}$ Should we be developing policies and programmes to bolster trust in the context of palliative care or, even more generally, in crises with a high death toll from 'invisible' causes?

Closely intertwined with the above issues are the wide cultural differences in understandings of illness, death and dying which, in turn, shape local practices in caring for and comforting the sick or deceased person. How can we ensure that we learn our lessons, again from the Ebola outbreak of 2014-2015, when Western values and practices of safety and public health clashed with local values and rituals around death and bereavement, each of them not only natural, but non-debatable, in the minds of those who held them? In many West African communities, local burials included a washing ceremony ${ }^{88}$ - a procedure that readily transmits Ebola. WHO reported that $60 \%$ of the Ebola cases in Guinea during the 2014 outbreak were related to burial practices. ${ }^{88}$ Precisely to minimise the risk of transmission, aid teams performed rapid burial ceremonies without familial notification. This bred contempt and mistrust. ${ }^{88}$ We are already witnessing the transformation of grieving and funeral practices across the world where COVID-19 social distancing rules are being enforced. It is critical that we acknowledge local rituals around death and bereavement as COVID-19 spreads and seek to build support among communities, religious leaders and funeral homes for adaptations to such rituals which are both compassionate and adhere to necessary infection control. ${ }^{89} 90$

Finally (though only within an initial set of contextual considerations as opposed to a systematic list of these), a populationlevel view also begins to identify the contribution of local actors, such as health workers or family members, who are usually the first responders in a humanitarian emergency. Local actors provide crucial care in the form of immediate and long-term practical and emotional support and simply sharing space with those who are suffering. It is nothing but a prejudice not to account for their extraordinary contributions to comforting the ill and dying and alleviating suffering. It is vital to consider how 
to integrate the resources of international humanitarian actors into existing care for the seriously ill and dying provided by local communities.

\section{FINAL REMARKS AND CONCLUSIONS}

As the globalisation of our world increases, we will be witnessing, experiencing and shaping more and more of its opportunities and abundance, of its challenges and tragedies together. This includes our humane and humanitarian response to alleviating the pain and suffering of the dying and terminally ill.

WHO guidance on the integration of palliative care and symptom relief in humanitarian response is and will continue to be key to enabling what is a moral imperative, even if the COVID-19 pandemic has been a too ferocious testing ground for its recent manual on the topic. It is of little value, apart from unpalatably righteous, to belabour the critical aspect of our argument. We hope that our paper will serve primarily as a source of ideas on improving successive documents on palliative care in humanitarian emergencies and crises. The core argument we have advanced is that applying a population-level ethics lens to the provision of palliative care in humanitarian settings brings up a whole host of ethical challenges that have been missed by an over-reliance on a predominantly clinical bioethics lens. We also suggest a range of considerations not captured by the utilitarian perspective-our default moral framework for when the good of the community needs to take priority over the good of the individual.

The addition of a population-level ethics lens is in no way sufficient for illuminating all ethical dilemmas falling outside the visual field of clinical bioethics. Population-level ethics is only one of many perspectives we need to incorporate in a robust and relevant ethical analysis of palliative care in humanitarian emergencies and crises. Another type of analysis which should receive urgent priority is that informed by humanitarian ethics. The latter can offer unique insights about, for instance, the intersections between the personal and the political and between the intimate, the operational and the strategic. As Slim asserts, 'it is in the realm of politics that humanitarian ethics finds its natural habitat and not simply the realm of medicine, nutrition, sanitation, economics or social work that make up the various fields of its practice. Doing humanitarian work at scale is doing politics'. ${ }^{91}$ Humanitarian ethics is, crucially, multilevel ethics: the intimate, where humanitarian workers such as doctors, engineers or social workers support individuals, and families and communities, acting in an individuals' best interests to alleviate suffering; the operational, where humanitarian managers need to make ethical decisions about areas of operation to support populations within camps, districts and regions (this level is likely to involve questions about resource allocation and political questions concerning cooperation with governments, other NGOs and sometimes armed groups); and the strategic, where leaders of humanitarian organisations must make global choices around funding, geographical and sectoral priorities and political partnerships, concerned with institutional interests and goals. ${ }^{91}$ It is easy to see how neither clinical bioethics, nor population-level ethics can offer sufficient insights into the operational and strategic levels of humanitarian ethics, both for the humanitarian health response in general and for strands of it addressing the needs of the seriously ill and the dying in particular.

The perspectives of disciplines such as anthropology, crosscultural psychology, legal studies, sociology, history, social geography, colonial and postcolonial studies, and political science can further advance the relevant ethical debate. For instance, ethical issues around opioid dependency, and the legal regimes associated with them, are a widely debated problem but one which we deprioritised so as to bring out more acute blind spots. Additional ethical issues can be identified, of course, by practising humanitarians and the recipients of their support. There must also be oft-forgotten perspectives which too can be exceptionally illuminating, such as those of interpreters and drivers, the often invisible intermediaries in humanitarian settings.

Beyond upholding the importance of a much richer ethical debate, we have also been arguing, be it largely indirectly, for a greater honesty and humility in it. It is important to have documents which outline and promote a positive vision. But when that vision is too distant from current and contextually diverse realities, such documents become irrelevant, even deserving of cynicism. It is particularly incomprehensible when this happens with regard to palliative and end-of-life care-a field defined by its ability to face some of the darkest and most frightening aspects of life and still preserve our hope and humanity.

We hope this paper can stir a debate among a broad variety of stakeholders, for the benefit of all whom we cannot save during humanitarian crises and who are experiencing grave suffering, whether physical, emotional, social or spiritual. And while only a small proportion of us will work firsthand to alleviate such suffering, most of us are its (distant) observers and, without exception, its potential victims. We cannot be looking away.

\section{Twitter Keona Jeane Wynne @KeonaWynne}

Contributors All authors contributed equally to this work.

Funding The authors have not declared a specific grant for this research from any funding agency in the public, commercial or not-for-profit sectors.

Disclaimer The views expressed in this paper are RC's and MP's views as an academic researchers and not a formal position of PalCHASE.

Competing interests MP reports that she is a Steering Group member of Palliative Care in Humanitarian Aid Situations and Emergencies network. RC reports that she is a member of the Palliative Care in Humanitarian Aid Situations and Emergencies network.

Patient consent for publication Not required.

Provenance and peer review Not commissioned; externally peer reviewed.

This article is made freely available for use in accordance with BMJ's website terms and conditions for the duration of the covid-19 pandemic or until otherwise determined by BMJ. You may use, download and print the article for any lawful, non-commercial purpose (including text and data mining) provided that all copyright notices and trade marks are retained.

\section{ORCID iDs}

Keona Jeane Wynne http://orcid.org/0000-0002-4051-8109

Mila Petrova http://orcid.org/0000-0001-7351-6815

Rachel Coghlan http://orcid.org/0000-0002-3596-4630

\section{REFERENCES}

1 Matzo M, Wilkinson A, Lynn J, et al. Palliative care considerations in mass casualty events with scarce resources. Biosecurity Bioterrorism Biodefense Strateg Pract Sci 2010

2 McCullough LB. Taking seriously the "what then?" question: an ethical framework for the responsible management of medical disasters. J Clin Ethics 2010;21(4):321-7.

3 Rosoff PM. Should palliative care be a necessity or a luxury during an overwhelming health catastrophe? J Clin Ethics 2010;21(4):312-20.

4 Powell RA, Schwartz L, Nouvet E, et al. Palliative care in humanitarian crises: always something to offer. Lancet 2017;389(10078):1498-9.

5 Knaul FM, Farmer PE, Krakauer EL, et al. Alleviating the access abyss in palliative care and pain relief - an imperative of universal health coverage: the Lancet Commission report. The Lancet 2018;391(10128):1391-454.

6 Marston J, De Lima L, Powell RA. Palliative care in complex humanitarian crisis responses. The Lancet 2015;386(10007).

7 Waldman E, Glass M. A field manual for palliative care in humanitarian crises. A field manual for palliative care in humanitarian crises. Oxford University Press 2019.

8 Palliative Care and COVID-19 [Internet]. Available: http://globalpalliativecare.org/ covid-19/ [Accessed cited 2020 Apr 21]. 
9 Dunant H. A memory of Solferino. Geneva: International Committee of the Red Cross, 1959.

10 WHO. Q\&A on coronaviruses (COVID-19) [Internet]. Available: https://www.who.int/ news-room/q-a-detail/q-a-coronaviruses [Accessed cited 2020 May 4].

11 WHO. Coronavirus disease 2019 [Internet]. Available: https://www.who.int/ emergencies/diseases/novel-coronavirus-2019 [Accessed cited 2020 Apr 21]

12 WHO. Integrating palliative care and symptom relief into the response to humanitarian emergencies and crises. Geneva, Switerland, 2018.

13 COVID-19: Operational guidance for maintaining essential health services during an outbreak [Internet]. Available: https://www.who.int/publications-detail/covid-19 operational-guidance-for-maintaining-essential-health-services-during-an-outbreak [Accessed 21 Apr 2020].

14 United Nations Office for the Coordination of Humanitarian Affairs (OCHA). Global humanitarian response plan: COVID-19. Geneva, 2020.

15 Wikler D, Brock D. Population-Level bioethics: mapping a new agenda. Glob bioethics Issues Conscienc twenty-firs century 2008.

16 Childress JF, Faden RR, Gaare RD, et al. Public health ethics: mapping the terrain. J Law Med Ethics 2002;30(2):170-8.

17 Slim H. Doing the right thing: relief agencies, moral dilemmas and responsibility in political emergencies and war. Disasters 1997;21(3):244-57.

18 Savulescu J, Wilkinson D. Who gets the ventilator in the coronavirus pandemic? These are the ethical approaches to allocating medical care - ABC News (Australian Broadcasting Corporation) [Internet]. Available: https://www.abc.net.au/news/202003-18/ethics-of-medical-care-ventilator-in-the-coronavirus-pandemic/12063536 [Accessed 26 Apr 2020].

19 Fink S. The Hardest Questions Doctors May Face: Who Will Be Saved? Who Won't? The New York Times [Internet]. Available: https://www.nytimes.com/2020/03/21/us/ coronavirus-medical-rationing.html? referringSource=articleShar [Accessed $26 \mathrm{Apr}$ 2020].

20 Feinstein MM, Niforatos JD, Hyun I, et al. Considerations for ventilator triage during the COVID-19 pandemic. Lancet Respir Med 2020.

21 Truog RD, Mitchell C, Daley GQ. The Toughest Triage - Allocating Ventilators in a Pandemic. N Eng/ J Med 2020;382(21):1973-5.

22 Emanuel EJ, Persad G, Upshur R, et al. Fair allocation of scarce medical resources in the time of Covid-19. N Eng/ J Med 2020;382(21):2049-55.

23 Wikler D. Rules doctors can follow to decide who gets care and who dies - The Washington Post [Internet]. Available: https://www.washingtonpost.com/outlook/ 2020/04/01/ration-ventilators-beds-coronavirus/ [Accessed 4 May 2020].

24 Anderson M, Gerber M. Introduction to humanitarian emergencies. Health in Humanitarian Emergencies Cambridge University Press, 2018: 1-8.

25 MSF 6 ways MSF is responding to the COVID-19 crisis [Internet]. Available: https:// msf.org.au/article/project-news/6-ways-msf-responding-coronavirus-covid-19-crisis [Accessed 4 May 2020].

26 Valles S. Philosophy of Population Health. In: Winther R, ed. Abingdon: Routledge, 2018: 224.

27 InDunn JR, Hayes MV. Toward a lexicon of population health. Can J Public Health 1999;90 Suppl 1:S7-10.

28 Krieger N. Epidemiology and the People's Health: Theory and Context 2011.

29 Garbutt G, Davies P. Should the practice of medicine be a deontological or utilitarian enterprise? J Med Ethics 2011;37(5):267-70.

30 Bayer R, Fairchild AL. The genesis of public health ethics. Bioethics 2004:18(6):473-92.

31 Mackay K. Perspectives utility and justice in public health. J Public Health 2017:40(3):413-8

32 Arah OA. On the relationship between individual and population health. Med Health Care Philos 2009;12(3):235-44

33 PalCHASE. Coronavirus and palliative care - Primary Care Unit. Cambridge Palliative Care and End of Life Group [Internet]. Available: https://www.phpc.cam.ac.uk/pcu/ palchase/coronavirus-and-palliative-care [Accessed 7 May 2020].

34 Nouvet E, Sivaram M, Bezanson K, et al. Palliative care in humanitarian crises: a review of the literature. Int J Humanitarian Action 2018;3(1).

35 ELRHA [Internet]. Available: https://www.elrha.org/about-us/ [Accessed 7 Oct 2019].

36 PalCHASE - Palliative Care in Humanitarian Aid Situations and Emergencies network [Internet]. Available: https://www.phpc.cam.ac.uk/pcu/palchase/ [Accessed 7 Oct 2019].

37 Etkind SN, Bone AE, Lovell N, et al. The role and response of palliative care and hospice services in epidemics and pandemics: a rapid review to inform practice during the COVID-19 pandemic. J Pain Symptom Manage 2020. doi:10.1016/j. jpainsymman.2020.03.029. [Epub ahead of print: 08 Apr 2020].

38 Arya A, Buchman S, Gagnon B, et al. Pandemic palliative care: beyond ventilators and saving lives. CMAJ 2020;192(15):E400-4

39 Christian MD, Devereaux A V, Dichter JR. Definitive care for the critically ill during a disaster: current capabilities and limitations: from a task force for mass critical care Summit meeting, January 26-27, 2007. Chicago IL: American College of Chest Physicians, 2008: 8-17.

40 WHO. WHO Director-General's opening remarks at the media briefing on COVID-19 11 March 2020 [Internet]. Available: https://www.who.int/dg/speeches/detail/whodirector-general-s-opening-remarks-at-the-media-briefing-on-covid-19-11-march2020 [Accessed 4 May 2020]

41 Fusi-Schmidhauser T, Preston NJ, Keller N, et al. Conservative management of COVID-19 Patients-Emergency palliative care in action. J Pain Symptom Manage 2020. doi:10.1016/j.jpainsymman.2020.03.030. [Epub ahead of print: 08 Apr 2020]
42 Sheikh K. Essential Drug Supplies for Virus Patients Are Running Low - The New York Times [Internet]. Available: https://www.nytimes.com/2020/04/02/health/coronavirusdrug-shortages.html [Accessed 27 Apr 2020].

43 Pilkington E. Death penalty states urged to release stockpiled drugs for Covid-19 patients | US news | The Guardian [Internet]. Available: https://www.theguardian.com/ us-news/2020/apr/13/death-penalty-states-coronavirus-stockpiled-drugs [Accessed 27 Apr 2020].

44 Radbruch L, Bausewein C. The calm before the storm - Germany prepares for the corona deluge | EAPC Blog [Internet]. Available: https://eapcnet.wordpress.com/2020/ 04/06/the-calm-before-the-storm-germany-prepares-for-the-corona-deluge/ [Accessed 27 Apr 2020].

45 Fowler RA, Fletcher T, Fischer WA, et al. Caring for critically ill patients with Ebola virus disease. perspectives from West Africa. Am J Respir Crit Care Med 2014;190(7):733-7.

46 Wakabi W. Fighting and drought worsen Somalia's humanitarian crisis. Lancet 2009

47 Wakabi W. Health and humanitarian situation worsens in Somalia. Lancet 2007;370(9594):1201-2.

48 Willmott L, White B, Gallois C, et al. Reasons doctors provide futile treatment at the end of life: a qualitative study. J Med Ethics 2016;42(8):496-503.

49 Horton R. A sea of suffering. Lancet 2019:391(10129):1465.

50 Goldstein J, Weiser B. Now Doctors Are the Ones Saying Goodbye to Coronavirus Patients - The New York Times [Internet]. Available: https://www.nytimes.com/2020/ 04/13/nyregion/coronavirus-nyc-doctors. html?referringSource=articleShare [Accessed 27 Apr 2020].

51 Almojera A. Coronavirus in New York: A paramedic's diary - BBC News [Internet]. Available: https://www.bbc.com/news/world-us-canada-52196815 [Accessed 27 Apr 2020].

52 Evelyn K. New York ER doctor who treated coronavirus patients dies by suicide | US news | The Guardian [Internet]. Available: https://www.theguardian.com/us-news/ 2020/apr/28/dr-lorna-breen-new-york-er-coronavirus [Accessed 4 May 2020].

53 Smith J Aloudat T. Palliative care in humanitarian medicine. Palliat Med 2017;31(2):99-101.

54 Fink S. Five days at Memorial. New York, 2013.

55 Holt A. Care homes plead for coronavirus help - BBC News [Internet]. Available: https://www.bbc.com/news/uk-england-52066318 [Accessed 27 Apr 2020].

56 BBC News. Coronavirus: Spanish army finds care home residents "dead and abandoned" - BBC News [Internet]. Available: https://www.bbc.com/news/worldeurope-52014023 [Accessed 27 Apr 2020].

57 Williamson L. Coronavirus: The grim crisis in Europe's care homes - BBC News [Internet]. Available: https://www.bbc.com/news/world-europe-52094491 [Accessed $27 \mathrm{Apr} 2020]$.

58 The New Humanitarian | How is coronavirus changing aid work? [Internet]. Available: https://www.thenewhumanitarian.org/opinion/2020/03/18/how-coronaviruschanging-your-work [Accessed 27 Apr 2020].

59 Math SB, Chaturvedi SK. Euthanasia: right to life vs right to die. Indian J Med Res 2012;136(6):899-902.

60 Bernheim JL, Deschepper R, Distelmans W, et al. Development of palliative care and legalisation of euthanasia: antagonism or synergy? BMJ 2008;336(7649):864-7.

61 Inbadas H, Zaman S, Whitelaw S, et al. Declarations on euthanasia and assisted dying. Death Stud 2017;41(9):574-84.

62 De Lima L, Woodruff R, Pettus K, et al. International association for hospice and palliative care position statement: euthanasia and physician-assisted suicide. J Palliat Med 2017;20(1):8-14.

63 Euthanasia and assisted suicide - NHS [Internet]. Available: https://www.nhs.uk/ conditions/euthanasia-and-assisted-suicide/ [Accessed 4 May 2020].

64 International Committee of the Red Cross - Treaties, States Parties and Commentaries [Internet]. Available: https://ihl-databases.icrc.org/ihl/COM/380-600037? OpenDocument [Accessed 7 Oct 2029].

65 Davis N. Euthanasia and assisted dying rates are soaring. But where are they legal? [Internet]. Available: https://www.theguardian.com/news/2019/jul/15/euthanasiaand-assisted-dying-rates-are-soaring-but-where-are-they-legal [Accessed 7 Oct 2019].

66 Antommaria AHM, Powell T, Miller JE, et al. Ethical issues in pediatric emergency mass critical care. Pediatr Crit Care Med 2011;12(6 Suppl):S163-8.

67 Di Blasi E. . Italians over 80 "will be left to die" as country overwhelmed by coronavirus [Internet]. Available: https://www.telegraph.co.uk/news/2020/03/ 14/italians-80-will-left-die-country-overwhelmed-coronavirus/ [Accessed $27 \mathrm{Apr}$ 2020].

68 Older voices in humanitarian crises: Calling for change [Internet], 2016. Available: www.truedesign.co.uk [Accessed 8 Oct 2019].

69 Zoraster RM. Comprehensive review vulnerable populations: Hurricane Katrina as a case study, 2019 [Accessed 8 Oct 2019].

70 Hoffman KM, Trawalter S, Axt JR, et al. Racial bias in pain assessment and treatment recommendations, and false beliefs about biological differences between blacks and whites. Proc Natl Acad Sci U S A 2016;113(16):4296-301.

71 Wyatt R. Pain and ethnicity. Virtual Mentor 2013;15(5).

72 Mossey JM. Defining racial and ethnic disparities in pain management. In: Clinical orthopaedics and related research. New York LLC: Springer, 2011: 469. 1859-70.

73 Bullock K. The influence of culture on end-of-life decision making. J Soc Work End Life Palliat Care 2011;7(1):83-98.

74 Koffman J, Burke G, Dias A, et al. Demographic factors and awareness of palliative care and related services. Palliat Med 2007;21(2):145-53. 
75 Aubrey A. What Explains The COVID-19 Race Gap? : Shots - Health News : NPR [Internet]. Available: https://www.npr.org/sections/health-shots/2020/04/18 835563340/whos-hit-hardest-by-covid-19-why-obesity-stress-and-race-all-matter [Accessed 4 May 2020].

76 John Hopkins University. State Testing Data by Race - Johns Hopkins Coronavirus Resource Center [Online]. Available: https://coronavirus.jhu.edu/data/us-state-dataavailability [Accessed 27 May 2020].

77 Platt L, Warwick R. Are some ethnic groups more vulnerable to COVID-19 than others? [Internet]. Available: www.nuffieldfoundation.org [Accessed 4 May 2020].

78 McLane H. Essay: Distributive justice during a pandemic - WHYY [Internet]. Available: https://whyy.org/articles/a-disturbing-medical-consensus-is-growing-heres-what-itcould-mean-for-black-patients-with-coronavirus/ [Accessed 8 May 2020].

79 Baker M, Fink S. At the Top of the Covid-19 Curve, How Do Hospitals Decide Who Gets Treatment? - The New York Times [Internet]. Available: https://www.nytimes.com/ 2020/03/31/us/coronavirus-covid-triage-rationing-ventilators.html [Accessed 4 May 2020].

80 Matheny Antommaria AH, Gibb TS, McGuire AL, et al. Ventilator triage policies during the COVID-19 pandemic at U.S. hospitals associated with members of the association of bioethics program directors. Ann Intern Med 2020. doi:10.7326/M20-1738. [Epub ahead of print: 24 Apr 2020].

81 British Medical Association. COVID-19 - ethical issues. A guidance note. London, 2020. https://www.bma.org.uk/media/2360/bma-covid-19-ethics-guidance-april2020.pdf

82 Matzo M, Wilkinson A, Lynn J, et al. Palliative care considerations in mass casualty events with scarce resources. Biosecur Bioterror 2009;7(2):199-210.
83 Subbarao I, Wynia MK, Burkle FM. The elephant in the room: collaboration and competition among relief organizations during high-profile disasters. J Clin Ethics 2010;21(4):328-34.

84 Guion P. Families in Liberia are paying Bribes for false certificates over Ebola deaths. Vice News 2014.

85 Maxmen A. How the Fight Against Ebola Tested a Culture's Traditions," National Geographic [Online]. Available: https://www.nationalgeographic.com/news/2015/ 01/150130-ebola-virus-outbreak-epidemic-sierra-leone-funerals/ [Accessed 27 May 2020].

86 Elliott V. Tackling Congo's Ebola outbreak "more than a public health response. New Humanit. 2019

87 The New Humanitarian | What's behind South Sudan's coronavirus inspired UNbacklash [Internet]. Available: https://www.thenewhumanitarian.org/news/2020/04/ 10/south-sudan-UN-coronavirus-backlash [Accessed 4 May 2020].

88 Manguvo A, Mafuvadze B. The impact of traditional and religious practices on the spread of Ebola in West Africa: time for a strategic shift. Pan Afr Med J 2015;22 Suppl $1: 9$

89 Bear L, Simpson N, Angland M, et al. A good death" during the Covid-19 pandemic in the UK: a report on key findings and recommendations 2020.

90 Faroog U. Coronavirus is changing how American Muslims hold funerals | Middle East Eye [Internet]. Middle East Eye. Available: https://www.middleeasteye.net/news/ coronavirus-muslims-change-funeral-practices-covid-19-pandemic [Accessed 9 May 2020].

$91 \mathrm{~S} \lim \mathrm{H}$. Humanitarian ethics : a guide to the morality of aid in war and disaster. Hurst \& Company 2015. 